\title{
Obstructive sleep apnea in children with cleft lip and/or palate: Results of an epidemiologic study
}

Anna R. Carlson ${ }^{1}$, Danielle L. Sobol ${ }^{2}$, Irene J. Pien ${ }^{2}$, Alexander C. Allori ${ }^{1}$, Jeffrey R. Marcus ${ }^{1}$, Stephanie E. Watkins ${ }^{7,9}$, Arthur S. Aylsworth ${ }^{4,5}$, Robert E. Meyer ${ }^{6}$, Luiz A. Pimenta ${ }^{3}$, Ronald P. Strauss ${ }^{3,7}$, Barry L. Ramsey ${ }^{7}$ and Eileen Raynor ${ }^{8 *}$

${ }^{1}$ Division of Plastic, Maxillofacial \& Oral Surgery; Duke Children's Hospital; Durham, NC, USA

${ }^{2}$ Duke University School of Medicine; Durham, NC, USA

${ }^{3}$ Craniofacial Center and Department of Dental Ecology; University of North Carolina - Chapel Hill (UNC-CH); Chapel Hill, NC, USA

${ }^{4}$ Department of Genetics; UNC-CH; Chapel Hill, NC, USA

${ }^{5}$ Department of Pediatrics; UNC-CH; Chapel Hill, NC, USA

${ }^{6}$ State Center for Health Statistics; Department of Health \& Human Services; Raleigh, NC, USA

${ }^{7}$ Center for Health Promotion \& Disease Prevention; UNC-CH; Chapel Hill, NC, USA

${ }^{8}$ Division of Otolaryngology - Head and Neck Surgery \& Communication Sciences, Duke Children's Hospital; Durham, NC, USA

${ }^{9}$ Department of Physical Therapy, Methodist University; Fayetteville, NC, USA

\begin{abstract}
Introduction: Children with cleft lip and/or palate are at increased risk of obstructive sleep apnea. The prevalence of obstructive sleep apnea in this population is unknown. The purpose of this study was to assess the frequency of obstructive symptoms and obstructive sleep apnea diagnosis in the cleft population. We hypothesized that obstructive symptoms present more frequently in children with orofacial clefts than unaffected children, and that frequency varies by cleft sub-type.

Methods: Children with isolated cleft lip and/or palate and children without birth defects born 1997-2003 were identified through the North Carolina Birth Defects Monitoring Program and birth records, respectively. A survey assessed airway obstructive symptoms, clinical diagnosis of obstructive sleep apnea, and prior polysomnography. Results were analyzed by frequency distributions and chi-square statistics.

Results: Obstructive symptoms were reported more frequently in cleft palate and cleft lip with palate than in cleft lip and unaffected children. Trouble sleeping and nighttime mouth breathing were reported in up to $37.9 \%$ of cleft palate and $45.5 \%$ of cleft lip and palate ( $\mathrm{p}<0.05$ ). There was no statistically significant difference between cleft lip and unaffected children. Obstructive sleep apnea was diagnosed in $6.3 \%$ of children with clefts and $0 \%$ of unaffected children ( $\mathrm{p}<0.0001$ ).

Conclusions: This study demonstrates a high frequency of obstructive symptoms in patients with cleft palate and cleft lip and palate. More children presented with obstructive symptoms than were diagnosed with obstructive sleep apnea. These children should be monitored for obstructive sleep apnea with a low threshold for polysomnography.
\end{abstract}

\section{Introduction}

Obstructive sleep apnea (OSA) is a disorder of intermittent partial and/or complete airway obstruction during sleep. OSA is common in children, with a prevalence of $1.2 \%-5.7 \%$ in the general pediatric population [1]. Signs and symptoms of OSA in children include snoring, labored breathing during sleep, apnea, gasping or snorting during sleep, enuresis, morning headache, daytime sleepiness, and learning difficulties. Significant morbidity may result from untreated OSA, including systemic or pulmonary hypertension, cardiac dysfunction, failure to thrive, neurocognitive difficulties, and behavioral problems.

Children with cleft lip and/or palate $(\mathrm{CL} / \mathrm{P})$ are known to be at increased risk for sleep disordered breathing and/or OSA [2-9], with a recent study showing that $14.7 \%$ of children with isolated CL/P screened positive for OSA [7]. Abnormal craniofacial structure and anatomic changes to the nose, nasopharynx, oropharynx, and/or palate associated with $\mathrm{CL} / \mathrm{P}$ may contribute to airway obstruction. Current literature regarding OSA in children with isolated CL/P is limited, with the majority of studies from single institutions or based on small cohorts undergoing a specific surgical intervention. The purpose of this study was to estimate the prevalence of obstructive airway symptoms and clinical diagnosis of OSA in children with CL/P. We hypothesized that the frequency of obstructive symptoms and OSA diagnosis is higher in children with $\mathrm{CL} / \mathrm{P}$ compared to children without birth defects, and that the frequency of symptoms and diagnosis varies by cleft sub-type.

\section{Methods}

The North Carolina Birth Defects Monitoring Program (a surveillance program of the North Carolina State Center for Health Statistics) was utilized to identify children with CL/P born from 1997-

Correspondence to: Eileen Raynor, Division of Otolaryngology - Head and Neck Surgery \& Communication Sciences, Duke Children's Hospital; Durham, NC, USA, E-mail: eileen.raynor@duke.edu

Key words: cleft lip and palate, obstructive sleep apnea

Received: April 01, 2017; Accepted: April 17, 2017; Published: April 20, 2017 
2003. Diagnoses and phenotypes were confirmed by chart review performed by a plastic surgeon, dentist, and geneticist. Children with known syndromes and Robin sequence were excluded per a previously described protocol [10]. 559 cases were confirmed as isolated, nonsyndromic CL/P. A group of unaffected children without known birth defects born 1997-2003 was randomly selected through review of North Carolina birth records.

All families of children with $\mathrm{CL} / \mathrm{P}$ and a random sample of unaffected children were mailed a survey assessing the presence and severity of OSA symptoms over the past 12 months. The questionnaire addressed common sleep apnea symptoms including trouble sleeping, breathing through the mouth at night, dry mouth in the morning, and snoring. Parents reported whether daytime sleepiness and falling asleep in class were of concern for their child. Survey questions were answered on a five point severity scale: not a concern, very minor concern, moderate concern, fairly bad concern, or severe concern. Prior clinical diagnosis of OSA and history of polysomnography in a sleep lab were reported.

Patients were classified into subgroups of CL/P: cleft lip with or without alveolus $(\mathrm{CL} \pm \mathrm{A})$, cleft palate only $(\mathrm{CP})$, and cleft lip with cleft palate $(\mathrm{CL}+\mathrm{P})$. Frequency distributions and chi square statistics were calculated to compare children with $\mathrm{CL} / \mathrm{P}, \mathrm{CL} \pm \mathrm{A}, \mathrm{CP}$, and $\mathrm{CL}+\mathrm{P}$ to unaffected children (SAS v. 9.3, Cary, NC). Less than 0.05 was considered a statistically significant $\mathrm{p}$-value.

\section{Results}

Completed surveys were received from $32 \%$ of the CL/P group $(n=176)$ and $27 \%$ of the group of unaffected children $(n=333)$. Demographics of the two groups were comparable (Table 1). The CL/P group was predominantly male $(60.2 \%)$, white $(76.7 \%)$, and in the $6^{\text {th }}$. $8^{\text {th }}$ grade $(40.9 \%)$ or $9^{\text {th }}-12^{\text {th }}$ grade $(36.9 \%)$ at the time the questionnaire was completed. Among children with isolated CL/P, $45.2 \%$ had $\mathrm{CL}+\mathrm{P}$, $33.3 \%$ had $\mathrm{CP}$, and $21.5 \%$ had $\mathrm{CL} \pm \mathrm{A}$.
Obstructive symptoms were more frequently reported in cleft phenotypes involving the palate

Symptoms of OSA were reported more frequently in children with $\mathrm{CP}$ and $\mathrm{CL}+\mathrm{P}$ than in those with $\mathrm{CL} \pm \mathrm{A}$ and unaffected children (Table 2). Trouble sleeping was reported in $36.2 \%$ of children with CP $(\mathrm{p}=0.0421)$ and $41.6 \%$ of children with $\mathrm{CL}+\mathrm{P}(\mathrm{p}=0.0001)$, compared to $25.2 \%$ of unaffected children (Figure 1). Mouth breathing at night was reported in $37.9 \%$ of $\mathrm{CP}(\mathrm{p}=0.0012)$ and $45.5 \%$ of $\mathrm{CL}+\mathrm{P}(\mathrm{p}<0.0001)$, compared to $18.6 \%$ of unaffected children (Figure 2). Dry mouth in the morning was reported in $31.0 \%$ of $\mathrm{CP}(\mathrm{p}=0.0007)$ and $36.4 \%$ of $\mathrm{CL}+\mathrm{P}(\mathrm{p}<0.0001)$, compared to $14.2 \%$ of unaffected children (Figure 3). Snoring was reported in $36.2 \%$ of $C P(p=0.0009)$ and $53.2 \%$ of $C L+P$ ( $\mathrm{p}<0.0001$ ), compared to $18.4 \%$ of unaffected children (Figure 4 ).

Children with $\mathrm{CL} \pm \mathrm{A}$ were significantly different from unaffected children only in frequency of snoring. Snoring was reported in $34.3 \%$ of the $\mathrm{CL} \pm \mathrm{A}$ group compared to $18.4 \%$ of unaffected children ( $\mathrm{p}=$ 0.0188 ). No statistically significant difference between any phenotype of $\mathrm{CL} / \mathrm{P}$ and unaffected children was noted in frequency of falling asleep in class or daytime sleepiness.

Polysomnography was more frequently completed in cleft phenotypes involving the palate

Polysomnographic evaluation was reported in $13.8 \%$ of children with $\mathrm{CL} / \mathrm{P}$ ( $\mathrm{p}>0.0001$ ), including $2.6 \%$ of $\mathrm{CL} \pm \mathrm{A}$ ( $\mathrm{p}=0.6008), 15.5 \%$ of $\mathrm{CP}(\mathrm{p}<0.0001)$, and $17.9 \%$ of $\mathrm{CL}+\mathrm{P}(\mathrm{p}<0.0001)$. Polysomnographic evaluation was reported in $1.5 \%$ of unaffected children.

OSA was more frequently diagnosed in patients with $\mathrm{CL} / \mathrm{P}$, predominantly in patients with cleft palate

OSA was diagnosed by a clinician in $6.3 \%$ of children with $\mathrm{CL} / \mathrm{P}$ ( $\mathrm{p}<0.0001$ ), including $2.6 \%$ of children with $\mathrm{CL} \pm \mathrm{A}$ ( $\mathrm{p}=0.0031), 14 \%$ of children with CP $(\mathrm{p}<0.0001)$, and $2.6 \%$ of children with $\mathrm{CL}+\mathrm{P}(\mathrm{p}=$ 0.0034 ) (Figure 5). OSA was diagnosed in $0 \%$ of unaffected children.

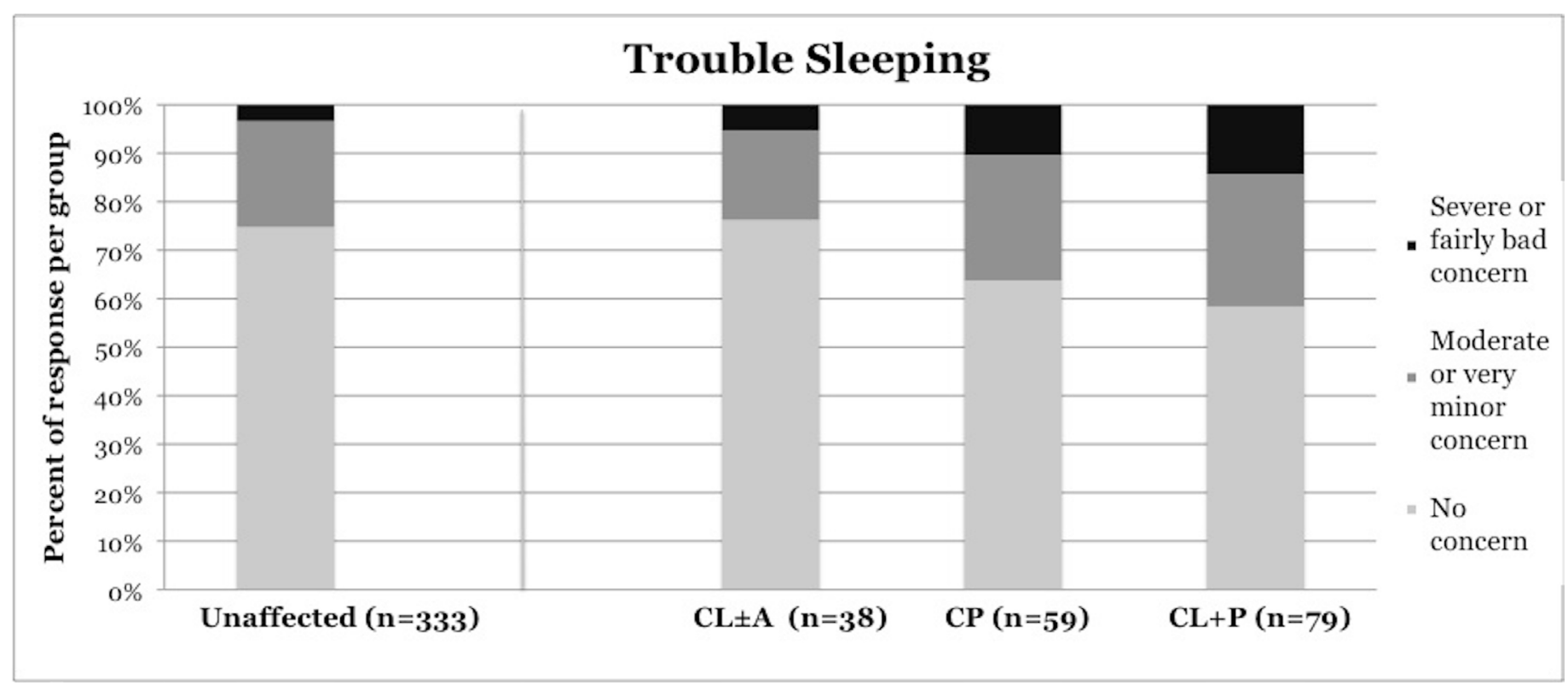

Figure 1. Reported frequency of trouble sleeping, stratified by cleft phenotype. Darker shadesof gray represent increasing severity of symptoms. CL/P, cleft lip and/or palate; $\mathrm{CL} \pm \mathrm{A}, \mathrm{cleft}$ lip with or without cleft alveolus; $\mathrm{CP}$, cleft palate; $\mathrm{CL}+\mathrm{P}$, cleft lip with cleft palate. 


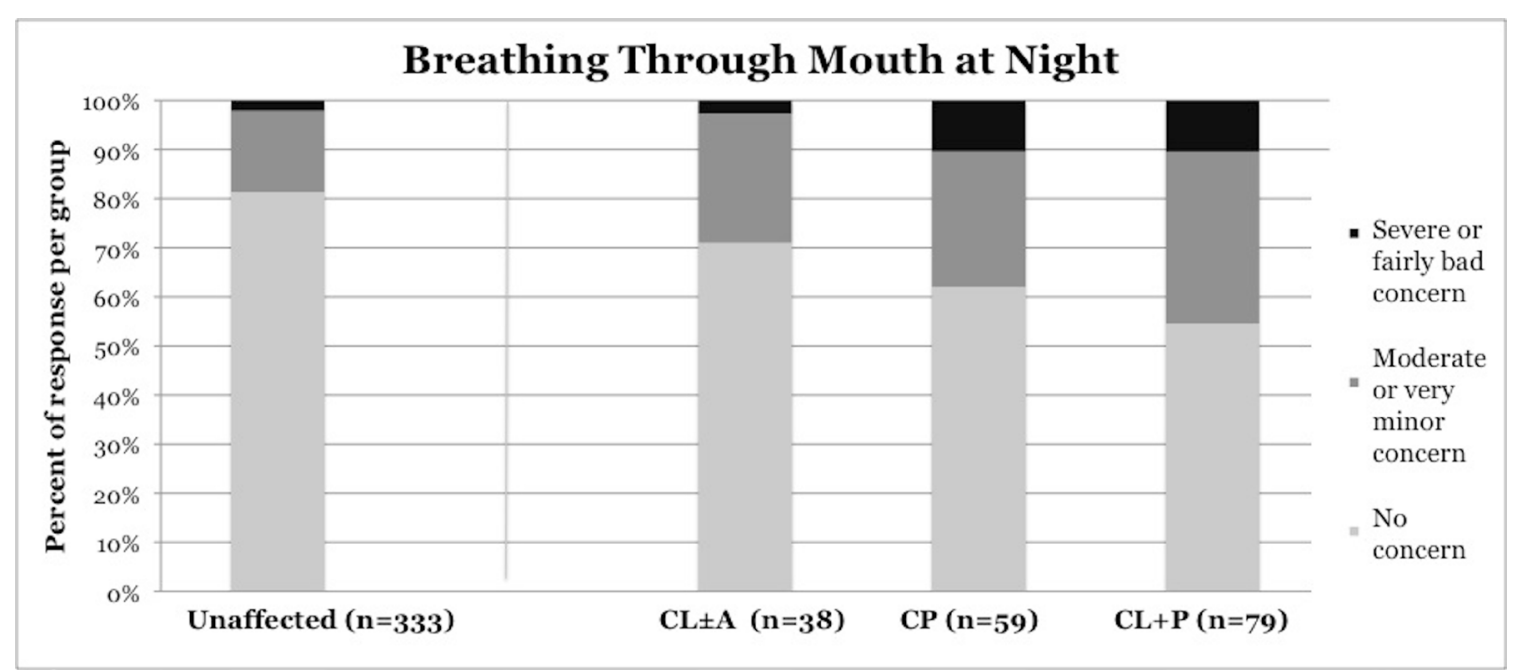

Figure 2. Reported frequency of mouth breathing at night, stratified by cleft phenotype. Darkershades of gray represent increasing severity of symptoms. $\mathrm{CL} / \mathrm{P}$, cleft lip and/or palate; $\mathrm{CL} \pm \mathrm{A}$, cleft lip with or without cleft alveolus; $\mathrm{CP}$, cleft palate; $\mathrm{CL}+\mathrm{P}$, cleft lip with cleft palate.

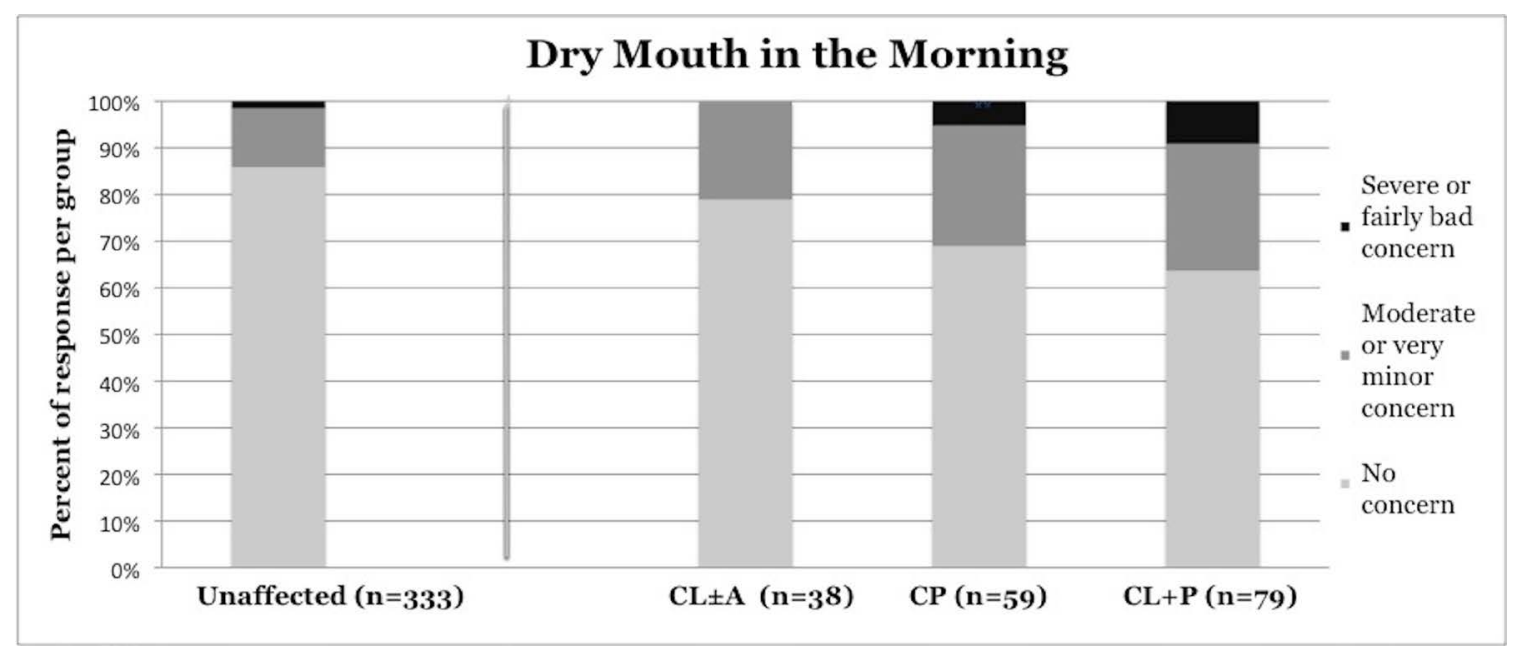

Figure 3. Reported frequency of dry mouth in the morning, stratified by cleft phenotype. Darkershades of gray represent increasing severity of symptoms. CL/P, cleft lip and/or palate; $\mathrm{CL} \pm \mathrm{A}$, cleft lip with or without cleft alveolus; $\mathrm{CP}$, cleft palate; $\mathrm{CL}+\mathrm{P}$, cleft lip with cleft palate.

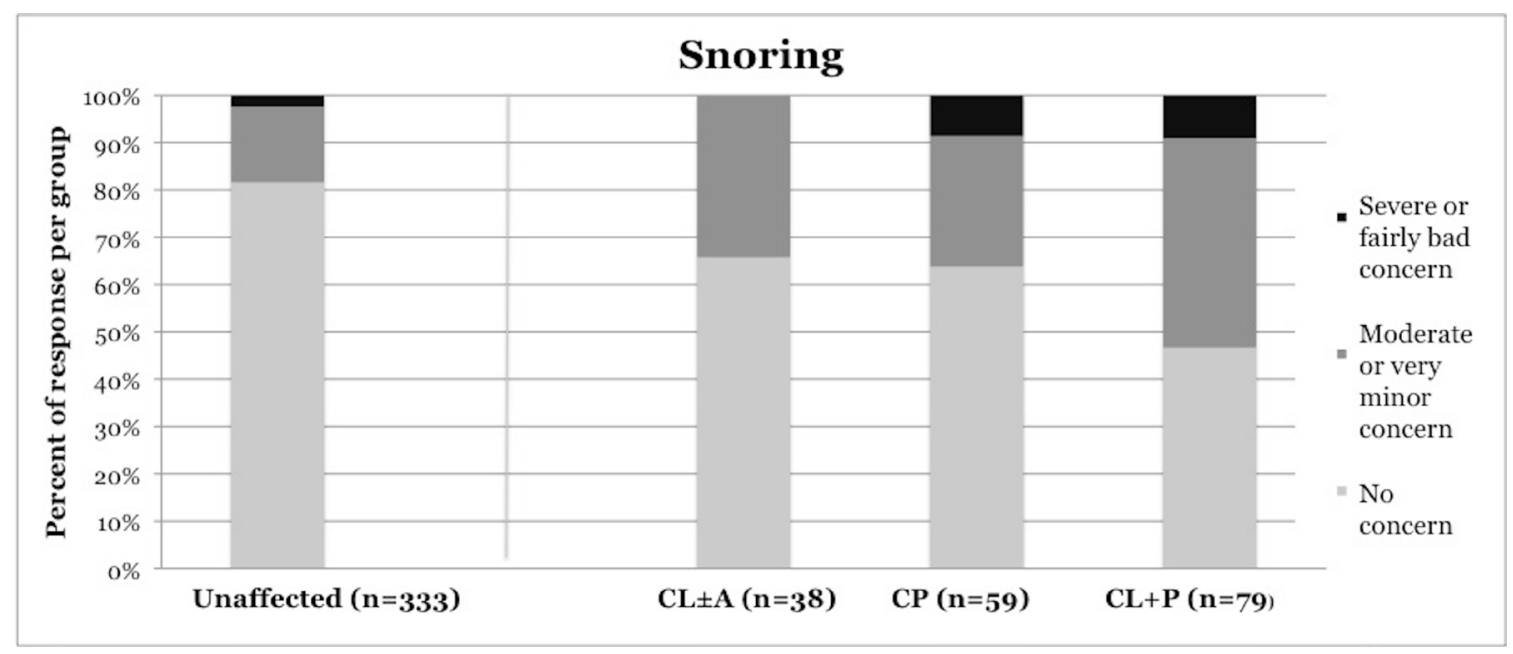

Figure 4. Reported frequency of snoring, stratified by cleft phenotype. Darker shades of grayrepresent increasing severity of symptoms. CL/P, cleft lip and/or palate; CL \pm A, cleft lip with or without cleft alveolus; $\mathrm{CP}$, cleft palate; $\mathrm{CL}+\mathrm{P}$, cleft lip with cleft palate. 
Table 1. Patient demographic

\begin{tabular}{|c|c|c|c|c|c|}
\hline Patient Characteristic & $\begin{array}{l}\text { Unaffected } \\
\text { Children }\end{array}$ & Overall CL/P & $\mathbf{C L} \pm \mathrm{A}$ & $\mathbf{C P}$ & $\mathbf{C L}+\mathbf{P}$ \\
\hline \# of respondents & 333 & 176 & $38(21.6 \%)$ & $59(33.5 \%)$ & $79(44.9 \%)$ \\
\hline Mean age (years) & $13.5 \pm 1.9$ & $13.4 \pm 2.0$ & $13.3 \pm 2.1$ & $14.0 \pm 1.9$ & $13.2 \pm 2.1$ \\
\hline \multicolumn{6}{|c|}{ Gender } \\
\hline Male & $171(51.4 \%)$ & $106(60.2 \%)$ & $25(65.8 \%)$ & $30(50.8 \%)$ & $51(64.6 \%)$ \\
\hline \multicolumn{6}{|c|}{ Year in School } \\
\hline $4^{\text {th }}-5^{\text {th }}$ grade & $45(13.5 \%)$ & $39(22.1 \%)$ & $9(23.7 \%)$ & $12(20.3 \%)$ & $18(22.8 \%)$ \\
\hline $6^{\text {th }}-8^{\text {th }}$ grade & $163(49 \%)$ & $72(40.9 \%)$ & $15(39.5 \%)$ & $19(32.2 \%)$ & $38(48.1 \%)$ \\
\hline $9^{\text {th }}-12^{\text {th }}$ grade & $124(37.2 \%)$ & $65(36.9 \%)$ & $14(36.8 \%)$ & $28(47.5 \%)$ & $23(29.1 \%)$ \\
\hline \multicolumn{6}{|c|}{ Ethnicity } \\
\hline American Indian & $6(1.8 \%)$ & $3(1.7 \%)$ & $1(2.6 \%)$ & $2(3.4 \%)$ & $0(0 \%)$ \\
\hline Asian & $5(1.5 \%)$ & $4(2.3 \%)$ & $1(2.6 \%)$ & $2(3.4 \%)$ & $1(1.3 \%)$ \\
\hline Black/African & $78(23.4 \%)$ & $26(14.8 \%)$ & $7(7.8 \%)$ & $8(13.6 \%)$ & $11(13.9 \%)$ \\
\hline Hispanic & $9(2.7 \%)$ & $8(4.5 \%)$ & $1(2.6 \%)$ & $2(3.4 \%)$ & $5(6.3 \%)$ \\
\hline White & $235(70.6 \%)$ & $135(76.7 \%)$ & $28(73.7 \%)$ & $45(76.3 \%)$ & $62(78.5 \%)$ \\
\hline
\end{tabular}

Note: $\mathrm{CL} / \mathrm{P}$ : cleft lip and/or palate; $\mathrm{CL} \pm \mathrm{A}$ : cleft lip with or without cleft alveolus; $\mathrm{CP}$ : cleft palate; $\mathrm{CL}+\mathrm{P}$ : cleft lip with cleft palate.

Table 2. Results per cleft phenotype.

\begin{tabular}{|c|c|c|c|c|}
\hline & Unaffected & $\mathbf{C L} \pm \mathbf{A}$ & CP & $\mathbf{C L}+\mathbf{P}$ \\
\hline & Children & $\mathbf{N}=\mathbf{3 8}$ & $\mathbf{N}=\mathbf{5 9}$ & $N=79$ \\
\hline & $\mathbf{N}=\mathbf{3 3 3}$ & & & \\
\hline \multirow[t]{2}{*}{ Trouble sleeping } & $25.2 \%$ & $23.7 \%$ & $36.2 \%$ & $41.6 \%$ \\
\hline & $(\mathrm{N}=83)$ & $(\mathrm{N}=9, \mathrm{p}=0.9557)$ & $(\mathrm{N}=21, \mathbf{p}=\mathbf{0 . 0 4 2 1})$ & $(\mathrm{N}=32, \mathbf{p}=\mathbf{0 . 0 0 0 1})$ \\
\hline Breathing through & $18.6 \%$ & $28.9 \%$ & $37.9 \%$ & $45.5 \%$ \\
\hline mouth at night & $(\mathrm{N}=62)$ & $(\mathrm{N}=11, \mathrm{p}=0.3935)$ & $(\mathrm{N}=22, \mathbf{p}=\mathbf{0 . 0 0 1 2})$ & $(\mathrm{N}=35, \mathbf{p}<\mathbf{0 . 0 0 0 1})$ \\
\hline Dry mouth in the & $14.2 \%$ & $21.1 \%$ & $31.0 \%$ & $36.4 \%$ \\
\hline morning & $(\mathrm{N}=47)$ & $(\mathrm{N}=8, \mathrm{p}=0.2317)$ & $(\mathrm{N}=18, \mathbf{p}=\mathbf{0 . 0 0 0 7})$ & $(\mathrm{N}=28, \mathbf{p}<\mathbf{0 . 0 0 0 1})$ \\
\hline \multirow[t]{2}{*}{ Snoring } & $18.4 \%$ & $34.2 \%$ & $36.2 \%$ & $53.2 \%$ \\
\hline & $(\mathrm{N}=61)$ & $(\mathrm{N}=13, \mathbf{p}=\mathbf{0 . 0 1 8 8})$ & $(\mathrm{N}=21, \mathbf{p}=\mathbf{0 . 0 0 0 9})$ & $(\mathrm{N}=41, \mathbf{p}<\mathbf{0 . 0 0 0 1})$ \\
\hline Daytime & $21.3 \%$ & $21.1 \%$ & $20.7 \%$ & $31.2 \%$ \\
\hline sleepiness & $(\mathrm{N}=71)$ & $(\mathrm{N}=8, \mathrm{p}=0.6893)$ & $(\mathrm{N}=12, \mathrm{p}=0.3069)$ & $(\mathrm{N}=24, \mathrm{p}=0.2047)$ \\
\hline Falling asleep in & $13.2 \%$ & $15.8 \%$ & $13.8 \%$ & $16.9 \%$ \\
\hline class & $(\mathrm{N}=44)$ & $(\mathrm{N}=6, \mathrm{p}=0.5136)$ & $(\mathrm{N}=8, \mathrm{p}=0.701)$ & $(\mathrm{N}=13, \mathrm{p}=0.4795)$ \\
\hline \multirow[t]{2}{*}{ OSA diagnosis } & $0 \%$ & $2.6 \%$ & $14.0 \%$ & $2.6 \%$ \\
\hline & $(\mathrm{N}=0)$ & $(\mathrm{N}=1, \mathbf{p}=\mathbf{0 . 0 0 3 1})$ & $(\mathrm{N}=8, \mathbf{p}<\mathbf{0 . 0 0 0 1})$ & $(\mathrm{N}=2, \mathbf{p}=\mathbf{0 . 0 0 3 4})$ \\
\hline Prior & $1.5 \%$ & $2.6 \%$ & $15.5 \%$ & $17.9 \%$ \\
\hline polysomnography & $(\mathrm{N}=5)$ & $(\mathrm{N}=1, \mathrm{p}=0.6008)$ & $(\mathrm{N}=9, \mathbf{p}<\mathbf{0 . 0 0 0 1})$ & $(\mathrm{N}=14, \mathbf{p}<\mathbf{0 . 0 0 0 1})$ \\
\hline
\end{tabular}

Note: $\mathrm{CL} / \mathrm{P}$ : cleft lip and/or palate; $\mathrm{CL} \pm \mathrm{A}$ : cleft lip with or without cleft alveolus; $\mathrm{CP}$ : cleft palate; $\mathrm{CL}+\mathrm{P}$ : cleft lip with cleft palate.

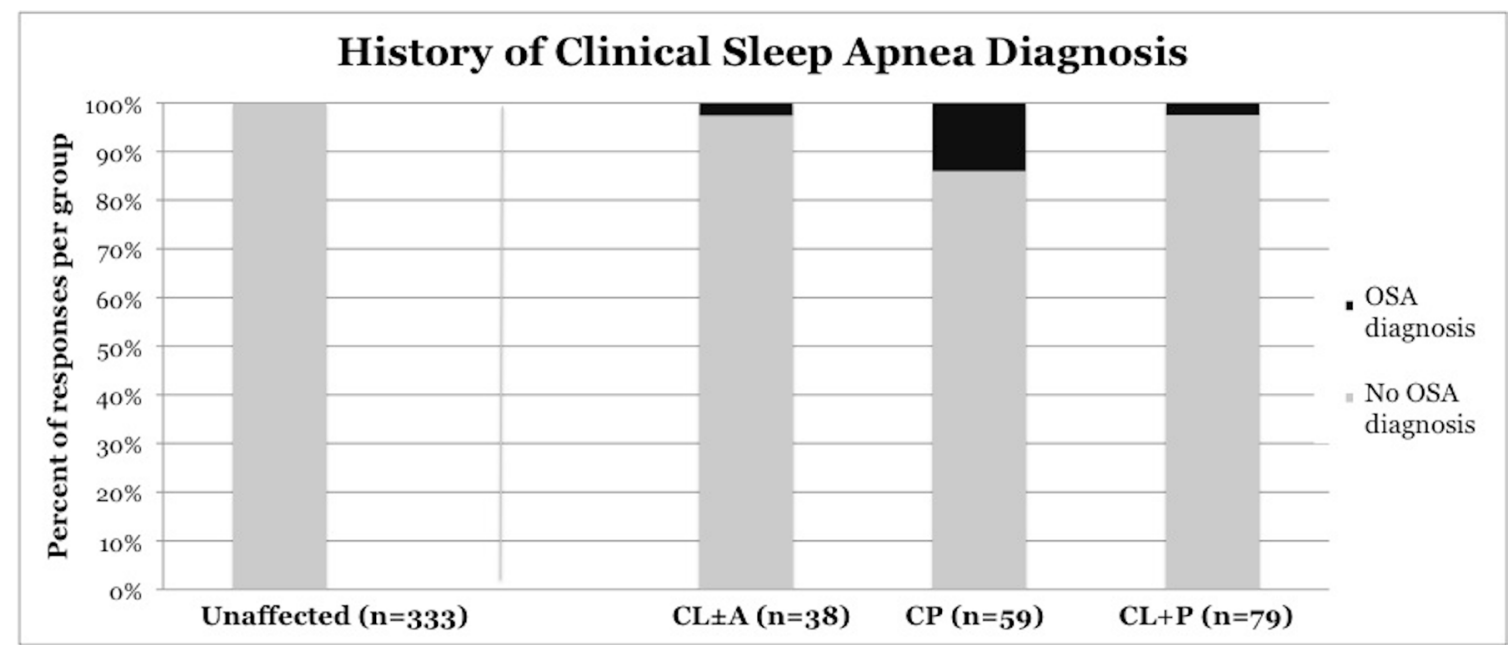

Figure 5. Frequency of clinical diagnosis of obstructive sleep apnea, stratified by cleftphenotype. CL/P, cleft lip and/or palate; $C L \pm A$, cleft lip with or without cleft alveolus; $C P$, cleft palate; CL+P, cleft lip with cleft palate. 


\section{Discussion}

\section{Presentations of OSA in children with $\mathrm{CL} / \mathrm{P}$}

Airway obstruction in children with $\mathrm{CL} / \mathrm{P}$ is frequently multifactorial and can occur at the level of the nose, nasopharynx, palate, and oropharynx. We categorize causes of OSA as follows: (1) primary anatomic OSA, (2) OSA in the setting of adenotonsillar hypertrophy (ATH), and (3) OSA in the setting of surgical correction of velopharyngeal insufficiency (VPI).

\section{Primary anatomic OSA}

Primary anatomic OSA describes OSA in children with CL/P in whom congenital airway anatomy is the only factor accounting for OSA. Abnormalities of bony anatomy in children with CL/P including a hypoplastic midface and retrognathic maxilla result in decreased cross sectional airway volume [3]. Dysfunction of muscles controlling the soft palate secondary to cleft anatomy can predispose to airway collapse and OSA [2]. Therefore, it is not surprising that our results suggest that children with palatal involvement $(\mathrm{CP}$ and $\mathrm{CL}+\mathrm{P})$ present more frequently with symptoms of OSA. Lastly, nasal airway obstruction, which may be present in patients with $\mathrm{CL}+\mathrm{P}[11]$, may predispose to airway collapse and OSA $[12,13]$.

\section{OSA in the setting of adenotonsillar hypertrophy}

Adenotonsillar hypertrophy is the most common cause of OSA in the general pediatric population. Patients with $\mathrm{CL} / \mathrm{P}$ and $\mathrm{ATH}$ are likewise prone to developing OSA, and the obstructive effects of ATH are exacerbated by the aforementioned anatomic features of patients with $\mathrm{CL} / \mathrm{P}$. Adenotonsillar anatomy in $\mathrm{CL} / \mathrm{P}$ patients must be carefully considered before attempting surgical correction of OSA by tonsillectomy and adenoidectomy. In addition to contributing to OSA, tonsillar hypertrophy predisposes to VPI. Large tonsils can partially occlude the space between the palate and posterior pharyngeal wall and hinder palatal closure. In this scenario, tonsillectomy should improve both OSA and VPI [2]. Adenoid hypertrophy, on the other hand, may protect against VPI because the adenoid in the posterior pharyngeal wall acts as a soft tissue pad against the palate, facilitating velopharyngeal closure. Adenoidectomy is thus to be undertaken cautiously in patients with $\mathrm{CL} / \mathrm{P}$ because of the risk of postoperative VPI. Partial or limited adenoidectomy may be an option, specifically, adenoidectomy with sparing of tissue around the level of Passavant's ridge.

In most cases, tonsillectomy and adenoidectomy is an effective treatment of OSA in children with CL/P and ATH. A single institution case series by Abdel Aziz found postoperative normalization of AHI in $70.6 \%$ of patients (12/17) with CP and ATH after tonsillectomy and/or partial adenoidectomy [2]. We recommend that children with CP or $\mathrm{CL}+\mathrm{P}$ and $\mathrm{OSA}$ attributable to ATH undergo tonsillectomy and partial adenoidectomy.

\section{OSA after surgical correction of velopharyngeal insufficiency}

$10-35 \%$ of patients with $\mathrm{CL} / \mathrm{P}$ will require surgical treatment of VPI, which decreases the cross-sectional area of the upper airway and can contribute to risk of sleep disordered breathing [14]. Options for surgical management of VPI include pharyngeal flap or sphincter pharyngoplasty. Airway obstruction and OSA have been reported after both of these surgical procedures, but may be more frequent and severe after pharyngeal flap surgery [15].

The incidence of OSA after surgical correction of VPI is unknown and varies widely in literature reports. Robison et al reported symptoms of sleep disordered breathing postoperatively in $24 \%$ of children with isolated CP (19/117) who underwent pharyngeal flap surgery [3], whereas Liao et al reported polysomnographic evidence of OSA in $93 \%$ of children $(26 / 28)$ with isolated CP six months postoperatively after pharyngeal flap surgery [16]. With appropriate clinical suspicion, this presentation of OSA is simple to recognize because of the preceding surgical event. For patients who develop OSA after surgical correction of VPI, treatment may include revision of the pharyngeal flap or pharyngeal sphincter. For patients with previous pharyngeal flap, options include dilation of lateral ports or conversion to sphincteroplasty. The decision to pursue this surgical modification or reversal involves weighing the risk of recurrent VPI against the risk of ongoing OSA. No evidence-based guidelines exist to direct this complex clinical decision.

For patients with evidence of OSA who present with VPI that requires surgical treatment, we suggest clinicians primarily consider sphincteroplasty to potentially avoid worsening of OSA. If sphincteroplasty is performed, close attention should be paid to creating adequate central port diameter to avoid exacerbation of OSA. An alternative surgical approach is a pharyngeal flap with close attention paid to creating lateral port size adequate to avoid exacerbation of OSA.

\section{Patient evaluation and management}

This is the first study to report the frequency of airway obstructive symptoms and OSA diagnosis using population-level data in children with $\mathrm{CL} / \mathrm{P}$. Our results indicate a significantly higher frequency of airway obstructive symptoms in children with $\mathrm{CL}+\mathrm{P}$ and $\mathrm{CP}$ compared to children with $\mathrm{CL} \pm \mathrm{A}$ and unaffected children.

No screening tools for OSA have been validated for use in children with CL/P. The Pediatric Sleep Questionnaire, a commonly used screening tool for OSA in otherwise healthy children, was recently shown to be poorly predictive of OSA in children with $\mathrm{CL} / \mathrm{P}$ [17]. The American Academy of Pediatrics (AAP) clinical practice guidelines for the diagnosis and management of childhood OSA state that the guidelines are not intended for application to children with craniofacial malformations [1]. Despite this caveat, the AAP guidelines may be the best available proxy for guidelines regarding OSA in the $\mathrm{CL} / \mathrm{P}$ population. The AAP guidelines state that any child who snores and presents with one additional sign or symptom of OSA should undergo polysomnography or be referred to a sleep specialist or otolaryngologist for further evaluation. If this guideline were applied to children with $\mathrm{CL} / \mathrm{P}$, our data suggest that approximately $38 \%$ of children with $\mathrm{CP}$ and $45 \%$ of children with $\mathrm{CL}+\mathrm{P}$ would undergo polysomnography. Although we believe polysomnography is underutilized in children with $\mathrm{CL} / \mathrm{P}$, we argue that a more detailed evaluation of airway symptoms is necessary in children with $\mathrm{CL} / \mathrm{P}$ before pursuing polysomnography in every child meeting these criteria.

Once snoring is confirmed by history, parents should be questioned regarding additional signs and symptoms of OSA, including labored breathing during sleep, gasping, snoring, apneas, sleep enuresis (with emphasis on enuresis that develops after at least six months of continence), headaches on awakening, and daytime sleepiness. History should be reviewed for ADHD or learning problems, which may be related to underlying OSA. Surgical history should be reviewed, noting any antecedent procedure to treat VPI, especially pharyngeal flap surgery. Nasal airway obstruction is frequently present in children with CL+P [17], thus, the possibility of nasal airway dysfunction as a source of airway obstructive symptoms should be addressed. The Nasal Obstruction Symptom Evaluation (NOSE) scale is an instrument 
validated in pediatric and adult populations for assessment of nasal airway obstruction in many different disease processes [18]. Use of this questionnaire may help to differentiate whether a patient's airway symptoms are due to isolated nasal obstruction, instead of OSA. If snoring and one additional sign of OSA are present and isolated nasal airway dysfunction is deemed unlikely, proceeding with polysomnography is warranted.

Nasal airway dysfunction and OSA may present synchronously and may be related. Multiple studies have shown an association of nasal airway obstruction with OSA. Specifically, OSA has been noted to be twice as prevalent in patients with nasal airway obstruction [12]. Increased nasal airway resistance creates proportionately increased negative pressure in the pharynx, predisposing to collapsibility of the pharyngeal cavity and likely contributing to the pathogenesis of OSA [13]. In accordance with these physiologic data, a recent study by Shuaib et al investigated the use of functional rhinoplasty to treat OSA in patients with nasal obstruction [19]. In the study, 26 patients who underwent functional rhinoplasty were evaluated with polysomnography and the NOSE scale preoperatively and postoperatively. Postoperatively, mean apnea-hypopnea index decreased by $35 \%(\mathrm{p}=0.013)$ in the overall study population, and by $57 \%(\mathrm{p}<0.01)$ when patients with BMI over 30 were excluded. These data suggest that functional rhinoplasty may be a treatment option for OSA in patients with nasal obstruction.

If nasal obstruction is thought to be a significant contributor to symptoms in patients with CL/P and OSA, the treatment in skeletally mature teenagers may include functional septorhinoplasty. The decision to pursue this surgery in younger children should be made cautiously. Septal surgery in children may contribute to midface growth disturbance, which is already a concern in the cleft population. Furthermore, removal of septal cartilage may compromise future cleft rhinoplasty.

A limitation of our study is the absence of polysomnography results to confirm clinical OSA diagnoses made by providers. An additional limitation is the absence of survey questions regarding pediatricspecific signs of OSA including enuresis or hyperactivity. In addition, OSA-related symptoms such as daytime sleepiness and falling asleep in class can be under-represented by this survey if completed by a parent, who may be unable to answer accurately. Another limitation is lack of surgical history to correlate with symptoms. We were, therefore, unable to differentiate which children with $\mathrm{CL} / \mathrm{P}$ had primary anatomic OSA versus OSA secondary to ATH or an operation intended to address VPI. Moreover, these data are only representative of the families who returned the questionnaire. It is possible that the prevalence of OSA may be different between families who did and did not return the survey.

\section{Conclusions}

In this study, we have demonstrated a high frequency of airway obstructive symptoms in children with $\mathrm{CP}$ and $\mathrm{CL}+\mathrm{P}$. Significantly more children with $\mathrm{CP}$ and $\mathrm{CL}+\mathrm{P}$ present with OSA symptoms than are diagnosed with OSA by a clinician or tested with polysomnography. Significant morbidity may be associated with untreated OSA, so accurate and timely diagnosis of OSA in this population is critical to prevent adverse cardiovascular, neurologic, and behavioral outcomes. Parents of children with $\mathrm{CL} / \mathrm{P}$ should be routinely questioned regarding symptoms of airway obstruction at cleft clinic visits. An effort should be made to delineate isolated nasal airway obstruction from OSA, especially in patients with $\mathrm{CL}+\mathrm{P}$. A NOSE screen may be useful for this task, and is a validated, simple, and inexpensive tool for use in clinics. Polysomnography should be considered in children with
$\mathrm{CL} / \mathrm{P}$ who present with snoring and one other sign of OSA, especially if symptoms cannot confidently be attributed to isolated nasal airway obstruction. When children with OSA are identified, treatment should be directed towards a suspected underlying etiology such as adenotonsillar hypertrophy or previous surgical intervention for VPI. Functional septorhinoplasty may represent a treatment option for obstructive sleep apnea in skeletally mature patients with $\mathrm{CL} / \mathrm{P}$, nasal airway obstruction, and OSA.

\section{Acknowledgements}

This work is a product of the North Carolina Cleft Outcomes Study. The primary goal of this study has been to identify new opportunities for intervention to improve educational, psychological/behavioral, and surgical outcomes for children with orofacial clefts. The results and opinions in this manuscript are those of its authors and do not necessarily represent the official view of the CDC. The authors would like to thank Dr. Cynthia Cassell for her assistance in study design.

\section{Related conference presentations}

Annual Scientific Meeting of the Southeastern Society of Plastic and Reconstructive Surgeons; June 6, 2015; Amelia Island, Florida, USA.

Annual Meeting of the North Carolina Society of Plastic Surgeons; October 2, 2015; Hot Springs, VA, USA.

\section{Funding}

“North Carolina Cleft Outcomes Study" CDC \#7U01DD000696.

\section{References}

1. Marcus CL, Brooks LJ, Draper KA, Gozal D, Halbower AC, Jones J, et al. (2012) Diagnosis and management of childhood obstructive sleep apnea syndrome. Pediatrics 130:576-584.

2. Abdel-Aziz M(2012) The effectiveness of tonsillectomy and partial adenoidectomy on obstructive sleep apnea in cleft palate patients. Laryngoscope 122:2563-2567. [Crossref]

3. Robison JG, Otteson TD (2011) Increased prevalence of obstructive sleep apnea in patients with cleft palate. Arch Otolaryngol Head Neck Surg 137:269-274. [Crossref]

4. MacLean JE, Hayward P, Fitzgerald DA, Waters K (2009) Cleft lip and/or palate and breathing during sleep. Sleep Med Rev 13:345-354. [Crossref]

5. Maclean JE, Waters K, Fitzsimons D, Hayward P, Fitzgerald DA (2009) Screening for obstructive sleep apnea in preschool children with cleft palate. Cleft Palate Craniofac $J$ 46:117-23. [Crossref]

6. Muntz H, Wilson M, Park A, Smith M, Grimmer JF (2008) Sleep disordered breathing and obstructive sleep apnea in the cleft population. Laryngoscope 118:348-53. [Crossref]

7. Silvestre J,Tahiri Y, Paliga JT, Taylor JA(2014) Incidence of positive screening for obstructive sleep apnea in patients with isolated cleft lip and/or palate. Plast Surg (Oakv) 22:259-263. [Crossref]

8. Silvestre J, Tahiri Y, Paliga JT, Taylor JA (2014) Screening for obstructive sleep apnea in children with syndromic cleft lip and/or palate. J Plast Reconstr Aesthet Surg 67:1475-1480. [Crossref]

9. Paliga JT, Tahiri Y, Silvestre J, Taylor JA (2014) Screening for obstructive sleep apnea in children treated at a major craniofacial center. J Craniofac Surg 25:1762-1765. [Crossref]

10. Aylsworth AS, Allori AC, Pimenta LA, Marcus JR, Harmsen KG, Watkins SE, et al (2015) Issues involved in the phenotypic classification of orofacial clefts ascertained through a state birth defects registry for the north carolina cleft outcomes study. Birth Defects Res A Clin Mol Teratol 103: 899-903. [Crossref]

11. Marcus J (2014) Nasal airway dysfunction in cleft lip nasal deformity: results of a cross-sectional population-based study. Annual Meeting of the Rhinoplasty Society; Montreal, Canada. 
12. Friedman M, Maley A, Kelley K, Leesman C, Patel A, Pulver T, et al. (2011) Impact of nasal obstruction on obstructive sleep apnea. Otolaryngol Head Neck Surg 144:10001004. [Crossref]

13. Zang HR, Li LF, Zhou B, Li YC, Wang T, Han DM (2012) Pharyngeal aerodynamic characteristics of obstructive sleep apnea/hypopnea syndrome patients. Chin Med J (Engl) 125:3039-3043. [Crossref]

14. Muntz HR (2012) Management of sleep apnea in the cleft population. CurrOpinOtolaryngol Head Neck Surg 20:518-521. [Crossref]

15. Sloan GM (2000) Posterior pharyngeal flap and sphincter pharyngoplasty: the state of the art. Cleft Palate Craniofac J 37:112-122. [Crossref]
16. Liao YF, Chuang ML, Chen PK, Chen NH, Yun C, Huang CS (2002) Incidence and severity of obstructive sleep apnea following pharyngeal flap surgery in patients with cleft palate. Cleft Palate Craniofac J 39:312-316.

17. Cielo CM, Silvestre J, Paliga JT, Maguire M, Gallagher PR, Marcus CL, et al. (2014) Utility of screening for obstructive sleep apnea syndrome in children with craniofacial disorders. Plast Reconstr Surg 134:434e-441e. [Crossref]

18. Stewart MG, Witsell DL, Smith TL, Weaver EM, Yueh B, Hannley MT (2004) Development and validation of the Nasal Obstruction Symptom Evaluation (NOSE) scale. Otolaryngol Head Neck Surg 130:157-163. [Crossref]

19. Shuaib SW, Undavia S, Lin J, Johnson CM Jr, Stupak HD (2015) Can functional septorhinoplasty independently treat obstructive sleep apnea? Plast Reconstr Surg 135:1554-1565. [Crossref]

Copyright: (C2017 Carlson AR. This is an open-access article distributed under the terms of the Creative Commons Attribution License, which permits unrestricted use, distribution, and reproduction in any medium, provided the original author and source are credited. 